\title{
Review of Chemical Constituents and Pharmacology of Brown-Rot Fungus Fomitopsis Pinicola
}

\author{
Muhammad Toseef Zahid ${ }^{1-2} \quad$ Muhammad Idrees $^{2} \quad$ Wei Ying $^{2} \quad$ Asmaa Hussein Zaki $^{2} \quad$ Iram Abdullah $^{2}$ \\ Bao Haiying ${ }^{1-2^{*}}$ \\ 1.Key laboratory of fungal resources and development and utilization, Jilin agriculture university Changchun, \\ Jilin 130118, China \\ 2.Engineering research center of the Chinese ministry of education for edible and medicinal fungi, Jilin \\ agriculture university, Changchun, Jilin 130118, China
}

\begin{abstract}
Fomitopsis pinicola is a well-known medicinal mushroom commonly used in Chinese traditional medicine and Korean folk medicine for many years, and it is believed as a non-toxic medicinal mushroom that has many clinical effects on the human body with no sub-acute toxic impacts. In recent years, the use of medicinal mushrooms is enhanced greatly. Several different principal chemical constituents are present in the fruiting bodies of F.pinicola. These principal compounds were extracted from fruiting bodies of $F$.pinicola, have medicinal qualities and give different pharmacological impacts in the human body. The motive of the current review paper was to intricate the principal chemical constituents that are extracted from F.pinicola fruiting bodies and demonstrate the pharmacological effects of these extracts. F.pinicola extracts have no toxic side effects on vital organs such as liver, kidney, heart, spleen, pancreas, lungs and brain. The present study describes that both low molecular weight and high molecular weight compounds that are present in the fruiting bodies of F.pinicola. This included many useful enzymes, steroids, triterpenes and triterpenes derivatives, anti-tumor active constituents, and health beneficial nutritious compounds. These principal compounds showed important medicinal effects on the human body by providing a shield effect to the internal organs against diseases and also heal the damaged tissues and organs. The pharmacological effects of F.pinicola active constituents include anti-tumor, anti-diabetic, antihyperlipidemic by controlling obesity, anti-oxidant effect, anti-microbial, anti-inflammatory and also showed an industrial waste treatment effect.
\end{abstract}

Keywords: Fomitopsis pinicola, Chinese traditional medicine, chemical constituents, pharmacological effects, waste treatment.

DOI: $10.7176 / J N S R / 10-2-07$

Publication date: January $31^{\text {st }} 2020$

\section{Introduction}

Fomitopsis pinicola karst was recognized in 1881 as a brown rot basidiomycete species present typically on coniferous and seldom on deciduous trees, widely distributed throughout Asia, Europe, and America. The basidiocarps of the species are perennial, sessile sporocarp, white to pinkish porous body, tinny and smooth basidiospores, and di to a trimitic hyphal arrangement with clamped generative hyphae. F.pinicola is also recognized as damaging decay mushroom in old-growth forests. It is commonly hosted by the acer, alnus, Elaeagnus, populous, picea, larix, pinus, and tilia. It has extensively been used in traditional Chinese medicine as Fomitopsis 11 species were found in boreal to the subtropical region of China and supposed to be a non-toxic mushroom. (Dai, 2012) In Korea, it has been traditionally used to treat different diseases. Numerous principal chemical constituents like steroids, triterpenes, and heterogalactan exert fruitful medicinal effects such as antiinflammatory, antidiabetic, antimicrobial, antitumor as well as powerful antioxidant activities. (Lee et al., 2008; Petrova et al., 2007) Furthermore, the presence of chitin and chitosan make it highly available as a nutritional supplement.(Kaya et al., 2015)

\section{Chemistry of F.pinicola:}

Fruiting bodies of $F$.pinicola constitute a lot of unique kinds of biologically active compounds. In recent years, many chemical extracts are prepared from fruiting bodies of F.pinicola that contain many useful enzymes like endoglucanase, xylanase, laccase, cellobiohydrolase, $\beta$-1,4-glucosidase, nutritional components such as chitan and chitosan, triterpenes, triterpene derivatives including triterpenic alcohol, lanostane triterpenoids, triterpene glycosides, steroids, biological active polysaccharides \{Endopolysaccharides and Exopolysaccharides\} and antitumor active constituents etc.

\subsection{Enzymes present in F.pinicola:}

2.1.1 Endoglucanase production by F.pinicola:

Cellulose is the chief element of the wood biomass, present abundantly, and a renewable source of energy. It has great potential for beneficial yield after its transformation, such as ethanol, soluble sugar, and industrial chemicals. 
Cellulose is a definite product of D-glucose units connected by $\beta-1,4$ - glycosidic linkages, hydrolyzed by enzymes such as $\beta$-glucosidases, endo- $\beta$-1,4-glucanase, and exoglucanases. $F$.pinicola culture filtrates, culture was grown on cellulose give rise to endoglucanase, after purification, SDS-PAGE analysis showed apparent molecular weight $32 \mathrm{kDa}$. Against CMC, the specific activity was $944 \mathrm{U} / \mathrm{mg}$ protein after the enzyme was purified 11-times. In purified endoglucanase, the partial amino acid succession highly similar to other fungi glycosyl hydrolase family 5 endo- $\beta$-1.4-glucanase. The $K_{m}$ value for CMC was $12 \mathrm{mg} \mathrm{CMC} / \mathrm{ml}$, and $K_{c m}$ was $670 / \mathrm{s}$. The purified endoglucanase had ability to hydrolyzed cellotetraose $\{\mathrm{G} 4\}$ as well as cellopentose $\{\mathrm{G} 5\}$. In short, according to results, cellotriose $\{\mathrm{G} 3\}$ and cellobiose $\{\mathrm{G} 2\}$ were not dissolved by endoglucanase.(Yoon et al., 2008)

2.1.2 Novel laccase from F.pinicola:

Laccase \{benzenediol: oxygen oxidoreductase\} is an important enzyme used for the detoxification of waste and conversion of azo dye. In the textile industry, processing used azo dye, and for dye products, the global market share is about $70 \%$. (Soares et al., 2001) Azo dyes are worldwide famous for their extensive usage in the textile processing industry as they are sharing $70 \%$ of dye products. From the F.pinicola culture filtrates, novel laccase was separated, and its yield reached a maximum level when cultivated at $25^{\circ} \mathrm{C}$ for about 8 days. Methodologies used for enzyme purification were hydrophobic interaction chromatography, ultrafiltration, gel filtration chromatography, and ion-exchange chromatography. The molecular mass of pure novel laccase was determined by zymography analysis and was $92 \mathrm{kDa}$. Gel filtration chromatography and sodium dodecyl sulfatepolyacrylamide gel electrophoresis $\{$ SDS-PAGE\} revealed that the molecular weight of laccase was $92 \mathrm{kDa}$. The isoelectric point of the enzyme was 3.8. According to the results, for enzyme activity, 3.8 was optimum $\mathrm{pH}$ and needed $80^{\circ} \mathrm{C}$ optimum temperature. Furthermore, an amino acid succession of the enzyme was DTHKAEIACRFKDLG at N-terminal. (Park \& Park, 2014)

2.1.3 Cellobiohydrolase by F.pinicola:

Cellulose is the main constituent of the cell wall of plants and the richest regeneratable biomass available on land. It is a strait biopolymer made of 100-10,000 $\beta$-D-glucopyranosyl sub-units interconnected by $\beta$-1,4-glucosidic linkages. Cellulases from the microbial source are important enzymes used in the paper industry, beer brewing industry, and alcohol fermentation industry. (YH. Zhang et al., 2006) A multienzyme system include $\beta$-glucosidase $\{B G L\}$, endo-1,4-glucanase $\{E G\}$ and cellobiohydrolase $\{\mathrm{CBH}\}$ needs to dissolute the cellulose. EG and $\mathrm{CBH}$ act together to depolymerize cellulose into oligosaccharides and as well as to cellobiose which by the action of BGL further transformed into glucose.(Bayer et al., Chanzy, 1998) From the back end of glucose chains, CBH cleaves cellobiose more effectively whereas EGs target more specifically the mid-region of the chains, likely unstructured part of cellulose 11.(Teeri et al., 1987) As F.pinicola yield highly active CBH, it was selected for further characterization after $\mathrm{CBH}$ screening. Sequential chromatography produced purified extracellular $\mathrm{CBH}$ from F.pinicola culture filtrate. According to SDS-PAGE and size-exclusion chromatography, the molecular weight was determined as $64 \mathrm{kDa}$ and indicated the monomeric nature of the enzyme. At $70^{\circ} \mathrm{C}$ F.pinicola $\mathrm{CBH}$ $\mathrm{t}_{1 / 2}$ value was $42 \mathrm{~h}$ with catalytic rate value $15.8 \mathrm{mM}_{-1 \mathrm{~S}-1}\left\{\mathrm{~K}_{\mathrm{cat}} / \mathrm{K}_{\mathrm{m}}\right\}$ for p-nitrophenyl- $\beta$-o-cellobioside. Moreover, amino acid sequences exhibited close similarity with glycoside hydrolase family 7 . Although comparative to other sources of $\mathrm{CBH}$ production, $\mathrm{CBH}$ from F.pinicola mushroom source is well-known due to high catalytic competency and thermostability.(Shin et al., 2010)

2.1.4 Thermostable xylanase from F.pinicola:

In the differentiated hardwood, xylans are the major hemicelluloses. They represent an enormous reserve of utilizable biomass, as hardwood consists of $25-32 \%$ hemicellulose, and softwood only has $15-25 \%$ hemicellulose.(Bhat \& Hazlewood, 2001) Xylans represent a considerable reservoir of fixed carbon in nature.(Morris et al., 1998) Most of the xylanases show optimal activity in slightly acidic medium with pH values 5.0-6.0 for most fungal xylanases and optimal temperature for xylanases activity between $40^{\circ} \mathrm{C}$ and $70^{\circ} \mathrm{C}$. (Ernest et al., 1987) $20 \%$ of the world's enzyme market comprised of xylanases, cellulases, and pectinases.(Polizeli et al., 2005) Extracellular xylanase was refined by using serial chromatography of $F$.pinicola culture supernatants, first used DEAE-Sepharose column later gel filtration column, and finally Mono Q column with fast protein liquid chromatography. The molecular weight of xylanase was $58 \mathrm{kDa}$, with monomeric nature that was determined by sodium dodecyl sulfate-polyacrylamide gel electrophoresis and size exclusion chromatography. According to findings, xylanase was hydrolytically active at an optimum temperature of $71^{\circ} \mathrm{C}$, required optimum $\mathrm{pH} 4.6$. Xylanase at $70^{\circ} \mathrm{C}$ showed $\mathrm{t}_{1 / 2}$ value of $33 \mathrm{~h}$. Catalytic efficacy of enzyme was $\left\{\mathrm{k}_{\text {cat }}=77.4 \mathrm{~s}-1, \mathrm{k}_{\text {cat }} / \mathrm{k}_{\mathrm{m}}=22.7 \mathrm{mg} / \mathrm{ml} / \mathrm{s}\right.$ \}. The amino acid sequence indicated major homology with hydrolases of GH family 10, showed that GH family 10 exhibit F.pinicola as a member.(Shin et al., 2010)

2.1.5 $\beta$-1,4-glucosidase from F.pinicola:

Cellulose and hemicellulose of the wood components mainly exploited by Brown-rot fungi and then promptly depolymerized the cellulose and leaving the surrounding lignin.(Kerem et al., 1999) Series way chromatography of F.pinicola culture supernatants was used to make $\beta-1,4$-glucosidase $\{$ BGL $\}$, sequence as first on a DEAEsepharose column then used gel filtration column and at the end Mono Q column with fast protein liquid chromatography. The molecular weight of BGL was checked by sodium dodecyl sulfate-polyacrylamide gel 
electrophoresis was $105 \mathrm{kDa}$, and size exclusion chromatography revealed it was $110 \mathrm{kDa}$, also explored that enzyme was monomeric. For enzyme hydrolytic efficacy, the required optimum temperature $50^{\circ} \mathrm{C}$ with an optimum $\mathrm{pH}$ of 4.5 . For $\mathrm{p}$-nitrophenyl- $\beta$ - D-glucopyranoside showed catalytic efficacy $\{\mathrm{kcat}=2,990 \mathrm{~s}-1, \mathrm{Km}=1.76$ $\mathrm{mM}, \mathrm{kcat} / \mathrm{Km}=1,700 \mathrm{mM}-1 \mathrm{~s}-1\}$. Amino acid sequences exhibited close similarity with hydrolase that indicated that it belongs to glycoside hydrolase family 3. BGL extracted from F.pinicola showed quite a difference with others because of highly potent and compact substrate targeting.(Joo et al., 2009)

\subsection{Chitosan and chitin yield from F.pinicola:}

Chitin is the most important structural component of fungal and plant cell wall as well as it is a homopolymer of $\mathrm{N}$-acetylglucosamine. Commercially obtained from crab shell waste and shrimp, and in the modern age, wastewater recycling, cosmetics products, and as well as textiles processing used chitin and chitin derived products.(Muzzarelli, 2009; Zhao et al., 2010) Chitin and chitosan also possess nutritional and medicinal values. In recent years scientists have carried out their research to find out the alternative sources of chitin and its derivatives from insects, corals, and some kinds of fungus.(Ifuku et al., 2011; Juárez-de La Rosa et al., 2012) F.pinicola is very important as medicinally and nutritionally throughout Asia and Northern hemisphere because of its major role in antimicrobial, antitumor, and antioxidant activities. After the isolation and characterization of chitin structure, it is revealed that $30.12 \%$ of dry fungus matter consisted of chitin that is quite a large amount, and in contrast to chitin, chitosan yield was 71.75 . It is also revealed that acetylation value for chitin was $72.5 \%$, and chitosan deacetylation value was $73.1 \%$. Results indicated that chitin degradation required the maximum temperature $\left\{\right.$ DTG max \} was $341{ }^{\circ} \mathrm{C}$ and was $265^{\circ} \mathrm{C}$ for chitosan. Chitin showed crystalline index $\{\mathrm{Crl}\}$ value 52 $\%$, and chitosan showed that value was $41 \%$. SEM examination revealed that chitin and chitosan surface morphology formed by nanofiber structure. The FTIR examination showed that chitin from F.pinicola is $\alpha$ form of chitan. The study showed that F.pinicola might use an alternative source of chitin and chitosan because of having a rich amount of them in fruiting bodies.(Kaya et al., 2015)

2.3 Small molecular weight constituents of F.pinicola:

2.3.1 Triterpenic alcohol:

From F.pinicola fruiting bodies, two chemical extracts were prepared, namely as butanol extract and chloroform extract to check their antibacterial activity against Artemia salina. Study results indicated that the chloroform extract contained high lethal effects, which were a sign of potential cytotoxicity; due to this reason, chloroform chemical composition is further analysed. chloroform extract under extensive chromatography led to the identification of 3-acetyloxylanosta-8,24-diene-21-ol, that was a new triterpenic acid, and this was the first report on it.(Petrova et al., 2007)

2.3.2 Triterpene derivatives:

Phytochemical examination of methanol and $n$-hexane of F.pinicola was done. This identified and separate triterpene derivatives and some aromatic compounds reduced from lignin. The isolation further identified modern natural products. These fresh compounds are pinicolol $\mathrm{C}$ and pinicolic acid $\mathrm{E}$, \{3-oxolanosta-7,9(11,24-trien15a,21-diol $\}$ and $\{16 \alpha$-hydroxy-3-oxolanosta-8,24-dien-21-oic acid $\}$ respectively. However, the results indicated a full set of ${ }^{13} \mathrm{C} N M R$ data of the steryl esters that were $3 \beta$-linoleyloxyergosta-7-one, $3 \beta$-linoleyloxyergosta-7,22diene and $3 \beta$-linoleyloxyergosta-7,24(28)-diene, that is recognized as a mixture in examined fungi. The HPLC and TLC verified that the hard surface of F.pinicola was rich with lanostane derivatives.(Rösecke \& König, 2000) 2.3.3 Steroids from fungus $F$.pinicola:

From F.pinicola, n-hexane and methanol extracts were prepared. Phytochemistry of these extracts elucidated six fresh lanostanoid derivatives. And by using mass and two dimensional NMR spectroscopy, their structures were examined. These newly founded natural products are 21-lanosta-7,9(11),24-trien-3-one, 3,4-secolanosta4(28),8,24-trien-3,21-dioic acid and 3b-hydroxy-16-oxolanosta-7,9(11),24-trien-21-oic acid, lanosta-7,9(11),24trien-3-one, 3,16-dioxolanosta-8,24-dien-21-oic acid, lanosta-7,9(11),24-trien-3b,15a,21-triol. Along with these compounds, the known compounds lanosta-7,9(11),24-trien-3b,21-diol and 3a-acetoxylanosta-8,24-dien-21-oic acid also determined. Furthermore, from the superficial hard part of fruiting bodies pinicolic acid, trametenolic acid, 21-hydroxylanosta-8,24-dien-3-one and 21-hydroxylanosta-7,9(11),24-trien-3-one were isolated.(Rösecke \& König, 1999)

2.4 Antitumor dynamic compounds in the fruiting body of F.pinicola:

Chloroform extract, petroleum extract, water extract, and Compound A were isolated from an extract of chloroform, antitumor activities of three extracts monomer compound studied in vitro, and in vivo. Chloroform extract effects on the immune organ were detected by measuring the thymus index, spleen index, and IL-2 levels of $\mathrm{H} 22$ mice. The results revealed that chloroform extract and compound A showed maximum inhibition rate. The inhibition rate was $52.97 \%$ on the dose of $200 \mathrm{mg} / \mathrm{kg} / \mathrm{d}$. Also, chloroform thymus index was greater than the normal group and CTX groups, with the significance of P-value more than 0.05 , which was close to the normal group. 
Spleen index was significantly higher than the normal group with P-value greater than 0.01 , close to the control, and CTX groups $(\mathrm{P}<0.01)$. Moreover, the contents of the IL-2 increased significantly. According to results, compound $\mathrm{A}$ had a better antitumor effect in vivo that showed a good dose relationship. There were significant differences with P-value less than 0.01 as compared with the control group. At a dose of $10 \mathrm{mg} / \mathrm{kg} / \mathrm{d}$, the inhibition rate was $52.31 \%$. Results indicated that compound A improves the immunity and increase the content of IL-2 and also had a good effect on the human breast cancer cells MCF-7 as well as on liver cancer cells SMMC-7721 in vitro. With a median effect dose $213.80 \mu \mathrm{g} / \mathrm{ml}$ and $123.03 \mu \mathrm{g} / \mathrm{ml}$, the maximum inhibition rates were $77.63 \%$ and $90.23 \%$, respectively. With compound A, the apoptosis rate of cancer was only $23.2 \%$ that is close to $20.9 \%$ of the negative control group. Depending on the results it is assumed that compound $\mathrm{A}$ is the main anti-tumor constituent of F.pinicola.(X. Sun et al., 2012)

\section{Pharmacology of $F$.pinicola:}

Fomitopsis pinicola is a non-toxic medicinal mushroom that is used in folk medicine for many years. Several extracts are prepared from their fruiting bodies that showed physiological effects. Its principle constituents such as triterpenes and its derivatives, enzymes, steroids, heteroglactan, glycosides, polysaccharides, chitan, and chitosan, giving physiological effect in the human body to cure a disease or used as a nutritional mushroom. The physiological effects include anti-tumor, anti-diabetic, anti-obesity, anti-oxidant, anti-inflammatory, antimicrobial and COX-1 and COX-2 inhibition, etc.

\subsection{Antitumor activity:}

3.1.1 Antitumor activity against S-180 tumor cells:

In recent years, many biological and chemical examinations were conducted on F.pinicola. Biological activity studies showed that $F$. pinicola extract showed antimicrobial, anticancer, and antioxidant properties. (Keller et al., 1996) To check the anti-cancer effect of F.pinicola, many extracts are prepared by using ethanol, petroleum ether, and ethyl acetate. For example, extracts of ethyl acetate and petroleum ether of $F$. pinicola revealed a cytotoxic effect on Hela cells as well as SMMC-7721 cells.(G. Ren et al., 2006) F.pinicola, used as a traditional remedy in various countries because of its anti-vascular disease and anti-inflammatory activity. The $F$. pinicola karst chloroform $\{\mathrm{FPKc}\}$ extract used to determine tumor-suppressive activity on S-180 tumor cells. In this, the HPLC method used to check the constituents of FPKc. The results of HPLC showed it might have, dehydroeburiconic acid, pachymic acid and ergosterol, in a range $0.25 \%, 17.8 \%$ and $10.5 \%$ respectively. The results also showed FPKc provided a significant inhibitory effect on proliferation of special cells included, S-180, HL-60, Eca-190 U937, and $\mathrm{K} 562$, causes cell morphology destruction and plasma membrane destruction, lead S-180 tumor cells late apoptosis with DNA destruction and S-phase inhibition. Mitochondria exhibited to have a major role in these changes. Results of in vivo examination proved that FPKc stopped the tumor and increased the life of mice with cancer. In vitro results revealed that the FPKs caused S-180 caspase-mediated cell death and inhibited the cell growth rhythm through the mitochondria.(Gao et al., 2017)

3.1.2 Anti-tumor activity against HeLa human cervical cancer cells:

The most common type of gynecological tumor is a cervical tumor. There are nearly 500000 newly diagnosed cases and more than 250,000 related deaths each year worldwide.(Bayu et al., 2016) Currently available treatments to cure the cancer are radiotherapy, chemotherapy, and surgery. F. pinicola is a non-toxic mushroom that extracts has many pharmacological activities, for example, anti-microbial, anti-fungal, anti-obesity, and anti-inflammatory properties. According to the report, the ethanol preparation of F.pinicola could encourage apoptotic cell death in A-549, MDA-MB231 and also HCT-116 cells, prevent SW-180 cell growth in vivo.(Wu et al., 2014) Furthermore, according to the chemical report, there were no lanstane triterpenes, ergosterol, and ergosterol derivatives in $F$. pinicola. The studies present that 3-acetoxylanosta-8,24-dien-21-oic acid (triterpenoid) that was infused from $F$. pinicola showed anti-tumor activity against HeLa cervical cancer cells. Cells were examined by MTT assay method, and programmed morphological death was check by staining technique called DAPI. By using another double staining methodology Annexin V-FITC/PI, apoptosis frequency was checked, and with the method of western blot analysis, apoptosis-proteins were investigated. The study concluded HeLa cervical cancer cell proliferation is greatly suppressed by the FPOA, $\mathrm{IC}_{50}$ range of $25.28,15.30$ and $11.79 \mu \mathrm{g} / \mathrm{ml}$ at 24,48 and 72 hours accordingly. Western blot examination explored that caspase-9 and caspase-3, both were covered quickly by FPOA treatment.(Li et al., 2018)

3.1.3 Cytotoxic effects on Hep G2 cells:

Triterpenoids widely exist in fungus, ferns, and plants. Triterpenoids exhibited various biological and pharmacological effects, particularly anti-tumor effects.(Chen et al., 2015) From the fruiting bodies of $F$. pinicola, 3-acetoxylanosta-8,24-dien-21-oic acid (FPOA) was processed. According to results, the molecular pathway of FPOA exerted apoptosis for the human Hep G2 cells and exerted cytotoxicity. With a half-maximal inhibitory concentration value $42.10 \mu \mathrm{M}$, FPOA was cytotoxic for Hep G2 cells. Flow cytometry results exhibited that FPOA enhanced the apoptosis rate in a dose-dependent manner. Western blot technique indicated that FPOA, decidedly 
elevated B-cell lymphoma 2 and caspase-9, cytochrome c, and caspase 3 release and lowered the poly \{ADP ribose polymerase level. As examined by Western blot procedure that FPOA specifically enhanced B-cell lymphoma 2 associated X/Bcl-2 ratio and cytochrome-c and made free caspase- 9 and caspase-3 and lowered the poly $\{\mathrm{ADP}\}$ ribose polymerase levels. The results showed that FPOA is a potential anti-cancer agent.(Song et al., 2018)

3.1.4 Migration inhibition and apoptotic effect:

Every year, colorectal cancer $\{C R C\}$ is increasing worldwide. Almost half of the affected patients died by this disease. (Jemal et al., 2011) In the USA, CRC is the third cause of death and considered the third most cause of death by a malignant tumor, commonly called cancer.(Siegel et al., 2013) The CRC incidence in Asian countries is less as compared to the USA, but it has been increasing in China rapidly.(Lu et al., 2003) F.pinicola karst \{FPK\} is a famous medicinal fungus in China, belongs to the Basidiomycota class. The FPK used in the treatment of many ailments like diabetes, heart diseases, malignancies, and so on. A study reported that $F$.pinicola ethanol yield has anti-cancer effects on S-180 malignant cells in vivo and in vitro and also showed that later stage set up apoptosis in lung, colorectal, breast and hepatoma malignant cells.(Wu et al., 2014) The studies exhibited FPK chloroform extract $\{\mathrm{FPKc}\}$ stop their immigration and give early apoptotic effect, but the possible mechanism has not illuminated in the studies. MTT assay showed that FPKc specifically ceased cells $\{\mathrm{SW}-480\}$ with the $\mathrm{IC}_{50}$ range of $190.28 \mu \mathrm{g} / \mathrm{ml}$. Wound healing and transwell examination revealed that immigration of SW-480 cells completely prohibited by FPKc. FPKc also drop-off the compact metalloproteinases- 2 and 9 manifestations. After chemical analysis with HPLC showed that the concentration of ergosterol (ES) was $105 \mu \mathrm{g} / \mathrm{mg}$. By using the staining procedure, namely as annexin V-FITC/PI staining and nuclear Hoechst 33342 staining and DNA fragmentation showed that cells apoptosis caused by FPKs and ES. It was also determined that one of the major components of FPKs was ES and thus considered as the active constituent.(Wang et al., 2014)

3.1.5 Anti-tumor activity against sarcoma-180 tumors:

Fungal extract in Far-Eastern is used as a nutritional supplement. In Asia, a wide range of mushrooms are used as nutritional diet, and in western countries in conjunction with allopathic medicines. (Yuen \& Gohel, 2005) Several biologically active compounds are present inside fungal extracts, so produce several pharmacological effects. Evidence indicated that fungal extracts consumptions might defend against some kind of cancers, such as breast cancer and gastrointestinal cancer.(Kim et al., 2002; M. Zhang et al., 2009) Some fungal species were involved in anti-cancer activities for different cells. The ethanol and water makings of $F$. pinicola was made to check the inhibitory effects on different tumorous cells. The results revealed that all the water yields exerted anti-cancer activities in vitro. On the other hand, 3-(4,5-methylthiazol-2-yl)-2,5-diphenyltetrazolium bromide assay exposed, water infusions showed lower inhibitory activities. According to the results, the F.pinicola ethanol infusion has more suppression of malignant cells and had a growth inhibitory ratio of $82.8 \%$ with $\mathrm{P}$ value less than $0.001 . F$. pinicola ethanol extraction also reduces the size of the tumor with increasing the life span of sarcoma-180 tumors having mice.(Wu et al., 2014)

3.1.6 Antitumor activity of seven lanostane type triterpenes from $F$. pinicola:

Seven lanostane type triterpenes including 3-keto-dehydrosulferenic acid, fomitopsin C, 3-acetyloxylanosta, dehydroeburiconic acid, 2-dien-21-oic acid, pinicolic acid-A, eburicicoic acid, and trametenolic acid-B were taken out from fruiting bodies of $F$.pinicola. In vitro assay, the structure-activity relationship of anti-tumor activity was discussed and checked on MCF-7, HepG2, HeLa cells, and A-549 cells by using the MTT procedure. According to the study results, seven compounds are more sensitive towards MCF-7 and $\mathrm{IC}_{5}$ for MCF-7. For the assay of compounds, H22 tumor mouse model was used. Compounds, 3-keto-dehydrosulferenic acid (KDA), and 2-dien21-oic acid (Lee et al.) had a distinct effect; the necrosis area and calculations had a direct relation. Moreover, compounds, KDA, DO and pinicolic acid-A had valuable antitumor impacts (dose $/ 20 \mathrm{mg}$ ) with $65.31 \%, 56.71 \%$, $58.72 \%$ inhibition, respectively. CTX group with $69.19 \%$ suppression in subcutaneous H22 implanted mice. These compounds play an important role in the manifestation of VEGF, cytokines, IL-4 and IFN- $\gamma$. Furthermore, structure-activity relation showed acetoxyl or carbonyl at C-3 and hydroxy at C-15 boost the anti-tumor effect of lanostane triterpenes.(Shi et al., 2017)

3.1.7 Anti-tumor and anti-oxidant property:

Anti-tumor and anti-oxidant activities of extract of $F$.pinicola was checked in vivo as well as in vitro. Salvage rate of anion radicals (superoxide) extended from 45.3 to 85.4 when concentrated from 500 to $700-\mu \mathrm{g} / \mathrm{ml}$, and the DPPH salvage rate raised from 50.4 to $88.1 \%$ when F.pinicola extract concentrated to $120 \mu \mathrm{g} / \mathrm{ml}$ from $60 \mu \mathrm{g} / \mathrm{ml}$. And linoleic acid clean rate increase from 35.6 to $90.6 \%$ when $F$.pinicola extract was incubated for almost about 12 hours. The study results indicated that the overall phenolic content of $F$.pinicola extracts was almost 10 to 17 times larger than P.nebrodensis and A.camphorate extracts. Glutathione is more frequently distributed in almost every cell and plays a key role as an anti-oxidant. It is low molecular weight, and non-proteinous compound maintains the thiol redox state (intracellularly) and protects the cells from xenobiotic organic chemical, heavy metals, and oxidative damage. Results showed that glutathione production was $20.0 \mu \mathrm{M} / \mathrm{g}$ of the liver that was 4 times greater than the control. Glutathione peroxidase activity was $8.3 \mathrm{U} / \mathrm{mg}$ of protein that was about 2.8 -times 
more than the activity level of the control group liver. Viability values of all human malignant cells were analysed by using $100 \mu \mathrm{g} / \mathrm{mL}$ ethanol extract for different cancer cells, then the viability of cells decreased with increased concentration of extract compared with hot water extract. Additionally, cell viability rates were 20 to $25 \%$ ( 3 fold higher than water extract) when did incubation of HeLa and Hep3B cells with $1000 \mu \mathrm{g} / \mathrm{mL}$ of methanol extract. Finally, it is concluded, F.pinicola extracts possess their noteworthy anti-tumor and anti-oxidant activities as compared to conventional extracts.(Choi et al., 2007)

\subsection{Effect on blood glucose and lipid profile:}

3.2.1 Anti-Diabetic effect:

DIABETES is the main cause of sickness and death globally. (Marx, 2002) According to the reports, mentioned that sickness caused by metabolic diseases such as diabetes, hyperlipidemia, and cardio problems are increasing day by day.(Korea, 2011) Unfortunately, there is not a complete medical treatment for DM and its complications. The motive to manage diabetes is to maintain the normal glycemic levels and prevention from diabetic complications by a balanced diet, routine exercise, and medication.(Koivisto, 1993) F.pinicola has been used as an antidiabetic in traditional medicine and believed as a non-poisonous mushroom.(Lee et al., 2008; Petrova et al., 2007) From the F.pinicola fruiting bodies, water extract $\{\mathrm{WE}\}$ and alkali extract $\{\mathrm{AE}\}$ were studied in diabetic rats, diabetes induced by streptozotocin $\{\mathrm{STZ}\}$. Four groups are made, one group is diabetes mellitus $\{\mathrm{DM}\}$ control group, second group normal group $\{\mathrm{NC}\}$, DM-WE group, and DM-AE group. The DM group lost weight gradually, whereas the NC weight increased. In contrast, the DM-AE group also increased the weight until approaching normal. The diet of DM-AE and NC was the same. This study showed that after fed with F.pinicola preparations, the blood glucose levels decreased as compared with the DM control group. Hyperglycaemia induced by STZ injection was almost inhibited by AE supplemented diet. Insulin levels also restored again after F.pinicola $\mathrm{AE}$ diet. Due to hyperglycaemia, the increased serum fructosamine levels also decreased with AE treatment. However, the pancreatic tissues that damaged by STZ treatment also healed with $F$.pinicola alkali extract $\{\mathrm{AE}\}$ treatment. F.pinicola Alkali extract $\{\mathrm{AE}\}$ exhibited the highest antidiabetic effect. Results, revealed that F.pinicola extractions manage diabetes either by raised insulin release or by healing pancreatic tissues.(Lee et al., 2008)

3.2.2 Effect on glucose and lipid metabolism:

In recent years mushrooms production has been increased because a variety of mushrooms are a way of nutrition. Compared with vegetables, the mushrooms are rich in protein and have almost every necessary vitamins and healthy minerals. Moreover, they have low-fat content and possess easily digestible carbohydrates, making them a proper less caloric diet.(Courvoisier, 1999) F.pinicola relates to the Basidiomycota, which has been extensively harvested and studied in japan and china, not only a traditional medication as well as a considered healthy food and for the treatment of diabetes.(Wald \& Law, 1995) In the studies, the pharmacologically of F.pinicola extract was checked on glucose and lipid metabolism within the blood. The diabetes was produced by using streptozotocin. At $30 \mathrm{~min}$ the blood concentration was same to control group, but after the administration of extract, the blood glucose levels instantly fell after $60 \mathrm{~min}$, and after $120 \mathrm{~min}$ the blood glucose concentration was $100.7 \mathrm{mg} / \mathrm{dL}$, which showed levels reached half relevant to the control group. After 20 days of the administration, glucose levels in the blood reduced from 362.0 to $204 \mathrm{mg} / \mathrm{dL}$ in diabetic rats. HDL- and LDL-cholesterol levels were $39.0 \mathrm{mg} / \mathrm{dL}$ and $13.2 \mathrm{mg} / \mathrm{dL}$ respectively; this exhibited an increase of $73 \%$ and a decrease of $76 \%$ respectively against the control group. The potential of aspartate aminotransferase and alanine transaminase activity increased, with suppression of the activity of lactate dehydrogenase, glutamic oxaloacetic transaminase, amylase, glutamic pyruvic transaminase, and alkaline phosphatase. The deviation was not seen in WBC, RBC, HB, hemocyte, platelet count, and hematocrit between test and control group. It is also revealed the F.pinicola extract is a potent agent in preventative and for the treatment of damaged liver and kidney cells.(Cha et al., 2009)

\subsection{Anti-obesity effect of F.pinicola:}

Increased body weight is a potential cause for health disorders according to increasing consensus. Obesity is the combination of excessive caloric intake with less physical work. It is rapidly spreading disorders globally, with many diseases, especially in well-established countries.(Spiegelman \& Flier, 2001) These clinical ailments, including hyperlipidemia, non-alcoholic fatty liver diseases (NAFLD), and insulin resistance.(Couillard et al., 2000) According to the reports, NAFLD is the second major root of death in the prevailing population, and clinically irreversible.(Saviano et al., 1997; Younossi et al., 2002) The anti-obesity effect of F.pinicola jeseng containing formulation $\{$ FAVA\} was checked. This formulation included the combination of four natural components named as Viscum album, Allium tuberosum, Acanthopanaxsenticosus, and F.pinicola jeseng. Mice that used a high-fat diet (HFD) are used and were treated with FAVA $\{200 \mathrm{mg} / \mathrm{kg} / \mathrm{day}\}$. The duration of the study was 12 weeks. In this duration, the anti-obesity effect, amelioration and non-alcoholic fatty liver diseases $\{$ NAFLD $\}$ were monitored. After treatment with FAVA, the body and white adipose tissue weight (Sariwati et al., 2017) was significantly decreased. The histological analysis explored, mice without reducing the diet intake led to amelioration of fatty liver in FAVA. With this, FAVA also reduced the leptin, insulin levels and lipid profiles as 
compared to the HFD mice. The experimental extract also diminished the mRNA (Lipogenic) manifestation from WAT with the cholesterol manufacturing in the liver. The study exhibited the suppressive effect of FAVA on plumpness and NAFLD in an obese rat model. So FAVA efficient remedy for reversing fat body and fatty liver because of excessive fats intake.(Jung et al., 2016)

3.4 Anti-inflammatory effect:

3.4.1 Anti-angiogenesis and anti-inflammatory effect of F.pinicola:

In the new age, health foods more frequently used because of maintaining good health. More specifically, mushroom's diets are consumed greatly, believed to have anti-tumor effects with low hazard to internal tissues. Among these mushrooms, F.pinicola is widely used and is reported that it provides good health, nutrition, and biological benefits. Chemical compounds found in $F$. pinicola include steroids, sesquiterpenes, lanostane triterpenoids, and triterpene glycosides. Furthermore, polysaccharides from mushrooms source found credible as a bioactive constituent, involved in anti-tumor as well as anti-inflammatory effects.(Hsiao et al., 2003) Only a few studies showed that polysaccharides from mushrooms source embraced in the suppression of angiogenesis.(Gu et al., 2004; Matsubara et al., 2005) F.pinicola is a medicinal mushroom that is being used for many years in medicine in Asia. When polysaccharides extracted from its 35-days cultured fungus and prepared its ethanolic extract, then its extracts showed no toxicity effect on an endothelial cell $\{E C s\}$. These extractions showed a strong suppressive effect on vascular endothelial growth factor $\{\mathrm{VEGF}\}$, regulated tube formation in ECs in a dose-dependent manner. It also showed that its ethanolic extract suppressed the production of interferon $\{$ IFN $\}$ - $\gamma$-induced inflammation marker, IP-10. According to results ethanolic extract and constituent polysaccharide of F.pinicola had no toxicity up to $1 \mathrm{mg} / \mathrm{ml}$ concentration, and the concentration required for anti-angiogenesis and antiinflammatory effect is $(10$ and $100 \mathrm{mg} / \mathrm{ml})$ individually. The ongoing study also showed that polysaccharide constituent gave high anti-angiogenic effect than ethanolic extract.(Cheng et al., 2008)

3.4.2 F.pinicola activity against cyclooxygenase (COX):

From the fruiting bodies of $F$. pinicola, two novel lanstane triterpenoids and ten fresh triterpene glycosides were separated. By using NMR and chemical methods, their structures were established, and the pharmacological effect for COX-1 and COX-2 was investigated. Namely as Fomitopinic acid A, Fomitopinic acid B, Fomitoside A, Fomitoside B, Fomitoside C, Fomitoside D, Fomitoside E, Fomitoside F, Fomitoside G, Fomitoside H, Fomitoside I and Fomitoside $J$ with molecular formula's as $\mathrm{C}_{30} \mathrm{H}_{48} \mathrm{O}_{5}, \mathrm{C}_{32} \mathrm{H}_{52} \mathrm{O}_{6}, \mathrm{C}_{35} \mathrm{H}_{54} \mathrm{O}_{8}, \mathrm{C}_{35} \mathrm{H}_{54} \mathrm{O}_{8}, \mathrm{C}_{35} \mathrm{H}_{54} \mathrm{O}_{7}, \mathrm{C}_{36} \mathrm{H}_{56} \mathrm{O}_{7}$, $\mathrm{C}_{37} \mathrm{H}_{58} \mathrm{O}_{9}, \mathrm{C}_{37} \mathrm{H}_{58} \mathrm{O}_{8}, \mathrm{C}_{38} \mathrm{H}_{60} \mathrm{O}_{8}, \mathrm{C}_{42} \mathrm{H}_{66} \mathrm{O}_{11}, \mathrm{C}_{36} \mathrm{H}_{58} \mathrm{O}_{8}$, and $\mathrm{C}_{37} \mathrm{H}_{60} \mathrm{O}_{8}$ respectively. The COX-1 and 2 inhibitory effects of the individual compounds were scrutinized. Aspirin was kept as a standard in the positive control group. According to the results, the trial compounds hindered the COX-2. Moreover, the findings are considered important for the evaluation of a selective inhibitor of COX-2, keeping in view the negative effects (gastric lesions) by COX-1 inhibition by drug aspirin and another one such as indomethacin. A very few natural compounds have been discovered that have COX-2 counter activity. This research demonstrated first time about potential targeted inhibition of COX-2 by lanostane triterpenoids as well as glycosides.(Yoshikawa et al., 2005)

\subsection{Anti-oxidant effect:}

3.5.1 The antioxidant property of F.pinicola:

Free radicals and reactive oxygen species are generated by conventional oxygen metabolism, and under environmental stress conditions, their high levels especially lead to tissue damage and other disorders.(Serviddio et al., 2013; Sies, 1997) Exotic anti-oxidants are usually administered to lessen the injurious results of free radical to the human body. In the modern age, the research hotspot is medicinal mushrooms for exploring anti-oxidants. Mushrooms polysaccharides showed counter effect against free radicals and reactive oxygen elements.(Ge et al., 2009; HH. Sun et al., 2009) According to the investigation, it is confirmed that fungal polysaccharides possessed a valuable anti-oxidant impact on 1-diphenyl-2-picrylhydrazyl (DPPH), superoxide anion and hydroxyls radical.(Huang et al., 2013) The research conducted with F.pinicola polysaccharides. The extracellular and intracellular polysaccharide extracted from F.pinicola and were examined. According to the outcomes, the molecular weight of extracellular and intracellular polysaccharides was $2.30 \times 10^{10} \mathrm{Da}$ and $4.07 \times 10^{5} \mathrm{Da}$, respectively. Both kinds of polysaccharides anti-oxidant activity were tested, including in-vitro activities on 1diphenyl-2-picrylhydrazyl (DPPH)as well as hydroxyl radicals, also protective effect on the cellular level of yeast cells by UV rays and hydrogen peroxide oxidative devastation. In a dose-contingent manner, both kinds of polysaccharides showed anti-oxidant activities. The results of the study showed that intracellular polysaccharides exhibited excellent anti-oxidant activity than extracellular polysaccharides.(Hao et al., 2016)

3.5.2 Anti-oxidant property of fermented products of F.pinicola:

By using scavenging DPPH, hydroxyl radical experiments and by a protection test model of oxidative damage to yeast cells, antioxidant activities of fermentation products of F.pinicola were examined. Results indicated that the F.pinicola fermentation concentrates and ethanol sediments, both, gave significant effects on scavenging radicals and oxidative damages as compared with the activity of natural antioxidant BHT. Moreover, effective 
concentrations of FPC and FPES that scavenged 50\% $\left(\mathrm{EC}_{50}\right)$ DPPH were 7.69 and $7.72 \mathrm{mg} / \mathrm{mL}$, respectively, while that value were 4.42 and $4.44 \mathrm{mg} / \mathrm{mL}$ on hydroxyl, $30.40 \mathrm{mg} / \mathrm{mL}$ on UV oxidative damage, 27.12 and $30.61 \mathrm{mg} / \mathrm{mL}$ on $\mathrm{H}_{2} \mathrm{O}_{2}$ oxidative damage, respectively. The study finally showed that fermentation products of $F$. pinicola showed significant antioxidant activity.(Hao et al., 2016)

3.6 Antimicrobial activity of F.pinicola:

3.6.1 Anti-microbial activity against B.sibtilis :

Fresh fruiting part of $F$.pinicola was lyophilized, and lyophilized mushroom $(300 \mathrm{~g})$ successively extracted with dichloromethane and methanol. The dichloromethane extract (13.7\%) showed antimicrobial activity in a TLC bioassay. (Hamburger \& Cordell, 1987) Phytochemical examination of dichloromethane extract of F.pinicola was done, that conducted to the segregation of novel lanostanoid entity, $3 \alpha$-carboxymethyl-3-hydroxymethylbutanoyloxy-lanosta-8,24-dien-21-oic acid was isolated. Furthermore additional seven known triterpenes

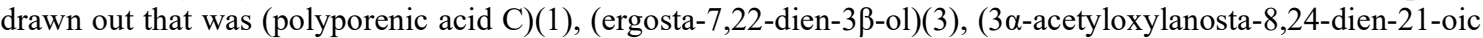
acid)(2), (21-hydroxylanosta-8,24-dien-3-one)(4), (trametenolic acid B)(6), (pinicolic acid A)(5), and (pachymic acid)(7) were isolated. Also, compound 1 was acetylated and made derivative $1 \alpha$, and compound 2 was hydrolyzed to made derivative $2 \alpha$ and then methylated to yield derivative $2 \beta$ - the molecular formula $\mathrm{C}_{37} \mathrm{H}_{58} \mathrm{O}_{7}$ established on the base of ${ }^{13} \mathrm{C}$ NMR and DEPT spectra. According to the results, compound 1,2,5,6,8 showed anti-microbial activity against $B$. subtilis in TLC bioassay. The quantities required to inhibit the $B$. subtilis were $1 \mu \mathrm{g}, 0.01 \mu \mathrm{g}$, $0.2 \mu \mathrm{g}, 2.5 \mu \mathrm{g}$, and $0.1 \mu \mathrm{g}$, respectively. In the positive control group, chloramphenicol used that was active at $0.01 \mathrm{~g}$. Derivatives $1 \alpha$ and $2 \alpha$ also showed activity at $0.05 \mu \mathrm{g}$ and $0.5 \mu \mathrm{g}$ accordingly. However when classical agar dilution assay using B.sibtilis, then not a single isolated compound and their derivatives exhibited inhibition at a concentration up to $50 \mu \mathrm{g} / \mathrm{ml}$.(Keller et al., 1996)

3.6.2 Anti-microbial activity against B.cereus :

To check anti-microbial activity, lanostane triterpenoids and one ergostane were separated from the American $F$. pinicola extract and also identified. (Liu et al., 2010b) These compounds are , 3-oxo-24-methyl-5a-lanost-8,25dien-21-oic acid (A), 3-oxo-5 $\alpha$-lanost-8,24-dien-oic acid (B), 16 $\alpha$-hydroxy-24-methylene-3-oxo-5 $\alpha$-lanost7,9(11)-dien-21-oic acid (C), 16 $\alpha$-hydroxy-24-methylene-3-oxo-5 $\alpha$-lanst-8-en-21-oic acid (D), 16 $\alpha$-acetyloxy-24methylene-3-oxo-5 $\alpha$-lanost-7,9(11)-dien-21-oic acid (E), and one ergostane in nature steroid, $22 E$-5 $\alpha$-ergosta7,9(11),22-trien-3 $\beta$-ol (F). Among these natural compounds, 3-oxo-24- methyl-5a-lanost-8,25-dien-21-oic acid was a fresh lanostane-triterpenoid, and by using HR-MS methodology, physical data, and 1D and 2D NMR, its structure was found. Against B.cereus, MIC assays were performed to check the anti-microbial activity of these natural compounds. The results showed that compounds $\mathrm{A}, \mathrm{B}, \mathrm{C}, \mathrm{D}$, and compound $\mathrm{F}$ exhibited feeble anti-B.cereus impact showed MIC values like 32, 16, 32, 32 and $64 \mu \mathrm{g} / \mathrm{ml}$ accordingly. The compound E displayed four-fold lessen activity with MIC range- $128 \mu \mathrm{g} / \mathrm{ml}$. To observe the specific anti-microbial pharmacology, the cytotoxicities of compounds, A to F were determined, $\mathrm{IC}_{50}$ were $500,500,1000,100,375$, and $1000 \mu \mathrm{g} / \mathrm{ml}$ for A to $\mathrm{F}$ compounds. These findings showed that compounds A,B,C, and F possessed a selective anti-microbial effect; this is because anti-microbial MICs are 15 to 30-fold lowered than their actual IC50s. Moreover, for D and E, the anti-bacillus results based on more common cytotoxicity, because their anti-microbial MICs are only 2-to 3-times lower than their normal $\mathrm{IC}_{50}$ s.(Liu et al., 2010a)

\subsection{Biodegradation of DDT:}

Various artificial chemicals, such as many various solvents, pesticides, and plasticizers, have been used in recent years. Chemical pesticides are used to protect crops. The most frequently used pesticide is 1,1,1-trichloro-2,2-bis (4-chlorophenyl) ethane commonly called as DTT.(Hai et al., 2012) This is extremely toxic to complex organisms because of having chlorine atom with their partial solubility and potential to cause lipophilic phase partition.(Sudharshan et al., 2012) Its common perseverance and toxicity are causing ability; it causes ecotoxicity so that the United States environmental protection agency has defined it as first-line action pollutant.(Foght et al., 2001) DTT is a highly lipophilic and endocrine disruptor and tends to pollute in foodstuff and adipose tissues to cause reproductive faults and breast cancers. So it is very important to make remediation to clean the DDT residues. In recent age, environmental friendly co-culture of bacteria and fungi is used to clean DTT residues. Bacillus subtilis, a bacteria with different volumes like $1 \mathrm{ml}, 3 \mathrm{ml}, 5 \mathrm{ml}, 7 \mathrm{ml}$, and $10 \mathrm{~mL}\left\{1 \mathrm{~mL}\right.$ is equal to $\left.6.7 \times 10^{8}\right\}$ were mixed with $10-\mathrm{mL}$ of $F$.pinicola culture for degradation of DTT for an incubation period of 7 days. And after 7 days of the incubation period, DTT degraded by $42 \%$ by F. pinicola. Results revealed when $10 \mathrm{~mL}$ of Bacillus subtilis was added to the media, which exhibited a high level of DTT deterioration ( $86 \%$ after 7 days duration of incubation). 1,1dichloro2,2bis(4chlorophenyl)ethane, 1,1dichloro2,2bis(4chlorophenyl)ethylene, and 1-chloro2,2-bis(4-chlorophenyl)ethylene commonly known as DDD, DDE and DDMU respectively, degraded products from DTT deterioration by F. pinicola an B.subtilis. Three pathways were proposed to transform DTT as follow, decholorination (to DDD), dehydrochlorination (to DDE) and conversion to DDMU.(Sariwati et al., 2017) 


\section{Conclusion}

Mushrooms are the best source of medicine and nutrition as its extracts give biological effects in the human body to treat many diseases. In Chinese and Korean traditional medicine, F.pinicola is used as a curative mushroom to overcome health problems without any bad effects. The purpose of this study was to provide a brief knowledge about the chemicals that are extracted from F.pinicola fruiting bodies and their pharmacological effects on the human body. According to this review, in the fruiting bodies of F.pinicola both large molecular and small molecular weight compounds are present, such as enzymes \{Endoglucanase, laccase, cellobiohydrolase, thermostable xylanase, $\beta$-1,4-glucosidase\}, valuable nutritional contents $\{$ chitin and chitosan\}, triterpenes, triterpene derivatives, steroids, and tumor-inhibiting constituents. This further demonstrated that F.pinicola extracts medicinal effect such as anti-tumor effects against various cell lines \{S180 tumor cells, HeLa human cervical cancer cells, Hep G2 cells, sarcoma-180 tumors, SW-480 cells \}, anti-diabetic effect, anti-hyperlipidemic effect, anti-oxidant activity, anti-obesity effect, anti-inflammatory activity, anti-microbial activity $\{$ B.subtilis, Bacillus cereus \}, immunological regulation in the body and cleaning of ecologically toxic pesticides and other chemicals. Nowadays, diabetes is one of the most leading causes of death, so there is a need to discover a natural remedy for treating this metabolic disorder. F.pinicola is used traditionally for many years to treat high blood glucose levels. Very few studies are conducted in this regard, and after review many research papers, it is a prospect to do deep research on the anti-diabetic and anti-hyperlipidemic effect of Medicinal mushroom F.pinicola.

\section{References}

Bayer, EA et al. (1998). Cellulose, cellulases and cellulosomes. Current opinion in structural biology 8(5), 548557.

Bayu, H et al. (2016). Cervical cancer screening service uptake and associated factors among age eligible women in Mekelle Zone, Northern Ethiopia, 2015: a community based study using health belief model. PloS one 11(3), e0149908.

Bhat, M et al. (2001). Enzymology and other characteristics of cellulases and xylanases. Enzymes in farm animal nutrition 7, 11-13.

Cha WS et al. (2009). Effect of Fomitopsis pinicola extract on blood glucose and lipid metabolism in diabetic rats. Korean journal of chemical engineering 26(6), 1696-1699.

Chen, G et al. (2015). Exopolysaccharide of Antarctic bacterium Pseudoaltermonas sp. S-5 induces apoptosis in K562 cells. Carbohydrate polymers 121, 107-114.

Cheng, JJ et al. (2008). Properties and biological functions of polysaccharides and ethanolic extracts isolated from medicinal fungus, Fomitopsis pinicola. Process Biochemistry 43(8), 829-834.

Choi, D et al. (2007). Effects ofFomitopsis pinicola extracts on antioxidant and antitumor activities. Biotechnology and Bioprocess Engineering 12(5), 516.

Couillard, C et al. (2000). Hyperleptinemia is more closely associated with adipose cell hypertrophy than with adipose tissue hyperplasia. International journal of obesity 24(6), 782.

Courvoisier, M et al. (1999). Les champignons comestibles dans le monde. Bul. Fed. Nat. Syn. Champ 82, 829837.

Dai, YC et al. (2012). Polypore diversity in China with an annotated checklist of Chinese polypores. Mycoscience $53(1), 49-80$.

Ernest, K et al. (1987). Production of thermostable xylanase by a thermophilic fungus, Thermoascus aurantiacus. Enzyme and Microbial Technology 9(1), 16-24.

Foght, J et al. (2001). Bioremediation of DDT-contaminated soils: a review. Biorernediation Journal 5(3), 225246.

Gao, Y et al. (2017). In Vitro and In Vivo Activity of Fomitopsis Pinicola (Sw. Ex Fr.) Karst Chloroform (Fpkc) Extract Against S180 Tumor Cells. Cellular Physiology and Biochemistry 44(5), 2042-2056.

Ge, Y et al., (2009). Polysaccharides from fruit calyx of Physalis alkekengi var. francheti: Isolation, purification, structural features and antioxidant activities. Carbohydrate polymers 77(2), 188-193.

$\mathrm{Gu}, \mathrm{G}$ et al. (2004). Synthesis of a 6V-sulfated mannopentasaccharide analogue related to PI-88. Carbohydrate research 339(6), 1155-1162.

Hai, FI et al. (2012). Pesticide removal by a mixed culture of bacteria and white-rot fungi. Journal of the Taiwan Institute of Chemical Engineers 43(3), 459-462.

Hamburger, MO et al. (1987). A direct bioautographic TLC assay for compounds possessing antibacterial activity. Journal of natural products 50(1), 19-22.

Hao, L et al., (2016). Characterization and antioxidant activities of extracellular and intracellular polysaccharides from Fomitopsis pinicola. Carbohydrate polymers 141, 54-59.

Hsiao, G et al., (2003). Antioxidative and hepatoprotective effects of Antrodia camphorata extract. Journal of Agricultural and Food Chemistry 51(11), 3302-3308.

Huang, QL et al. (2013). Fractionation, characterization and antioxidant activity of exopolysaccharides from 
fermentation broth of a Cordyceps sinensis fungus. Process Biochemistry 48(2), 380-386.

Ifuku, S et al. (2011). Preparation of chitin nanofibers from mushrooms. Materials 4(8), 1417-1425.

Jemal, A et al. (2011). Global cancer statistics. CA: A cancer journal for clinicians 61(2), 69-90.

Joo, AR et al. (2009). Purification and characterization of a $\beta$-1, 4-glucosidase from a newly isolated strain of Fomitopsis pinicola. Applied microbiology and biotechnology 83(2), 285-294.

Juárez-de La Rosa, B et al. (2012). Effects of thermal treatments on the structure of two black coral species chitinous exoskeleton. Journal of Materials Science 47(2), 990-998.

Jung, HY et al. (2016). A fomitopsis pinicola jeseng formulation has an antiobesity effect and protects against hepatic steatosis in mice with high-fat diet-induced obesity. Evidence-Based Complementary and Alternative Medicine 2016.

Kaya, M et al. (2015). Physicochemical properties of chitin and chitosan produced from medicinal fungus (Fomitopsis pinicola). Food Biophysics 10(2), 162-168.

Keller, AC et al. (1996). Antimicrobial steroids from the fungus Fomitopsis pinicola. Phytochemistry 41(4), 10411046.

Kerem, $\mathrm{Z}$ et al. (1999). Biodegradative mechanism of the brown rot basidiomycete Gloeophyllum trabeum: evidence for an extracellular hydroquinone-driven fenton reaction. FEBS letters 446(1), 49-54.

Kim, HJ et al. (2002). Dietary factors and gastric cancer in Korea: A case-control study. International journal of cancer 97(4), 531-535.

Koivisto, VA et al. (1993). Insulin therapy in type II diabetes. Diabetes Care 16(Supplement 3), 29-39.

Korea, S et al. (2011). Annual report on the cause of death statistics 2010. Daejeon: Statistics Korea 48.

Lee, SI et al. (2008). Antihyperglycemic effect of Fomitopsis pinicola extracts in streptozotocin-induced diabetic rats. Journal of medicinal food 11(3), 518-524.

$\mathrm{Li}, \mathrm{X}$ et al. (2018). FPOA induces apoptosis in HeLa human cervical cancer cells through a caspase-mediated pathway. Oncology letters 15(6), 8357-8362.

Liu, XT et al. (2010). Antibacterial compounds from mushrooms II: lanostane triterpenoids and an ergostane steroid with activity against Bacillus cereus isolated from Fomitopsis pinicola. Planta medica 76(05), 464466.

Liu, XT et al. (2010). Antibacterial compounds from mushrooms I: a lanostane-type triterpene and prenylphenol derivatives from Jahnoporus hirtus and Albatrellus flettii and their activities against Bacillus cereus and Enterococcus faecalis. Planta medica 76(02), 182-185.

Lu, JB et al. (2003). Epidemiology of gastroenterologic cancer in Henan Province, China. World journal of gastroenterology 9(11), 2400.

Marx, J et al. (2002). Unraveling the causes of diabetes: American Association for the Advancement of Science.

Matsubara, K et al. (2005). Effects of middle molecular weight fucoidans on in vitro and ex vivo angiogenesis of endothelial cells. International journal of molecular medicine 15(4), 695-699.

Morris, DD et al. (1998). Cloning of the xynB Gene fromDictyoglomus thermophilum Rt46B. 1 and Action of the Gene Product on Kraft Pulp. Appl. Environ. Microbiol 64(5), 1759-1765.

Muzzarelli, RA. 2009. Chitins and chitosans for the repair of wounded skin, nerve, cartilage and bone. Carbohydrate polymers 76(2), 167-182.

Park, N et al. (2014). Purification and characterization of a novel laccase from Fomitopsis pinicola mycelia. International journal of biological macromolecules 70, 583-589.

Petrova, A et al. (2007). A new triterpenic alcohol from Fomitopsis pinicola. Natural product research 21(5), 401405.

Polizeli, M et al. (2005). Xylanases from fungi: properties and industrial applications. Applied microbiology and biotechnology 67(5), 577-591.

Ren, G et al. (2006). Evaluation of cytotoxic activities of some medicinal polypore fungi from China. Fitoterapia, $77(5), 408-410$.

Ren, Y et al. (2015). Cytotoxic and natural killer cell stimulatory constituents of Phyllanthus songboiensis. Phytochemistry 111, 132-140.

Rösecke J, König WA. 1999. Steroids from the fungus Fomitopsis pinicola. Phytochemistry 52(8), 1621-1627.

Rösecke J, König WA. 2000. Constituents of various wood-rotting basidiomycetes. Phytochemistry, 54(6), 603610.

Sariwati, A et al. (2017). Abilities of Co-cultures of Brown-Rot Fungus Fomitopsis pinicola and Bacillus subtilis on Biodegradation of DDT. Current microbiology 74(9), 1068-1075.

Saviano, MC et al. (1997). Liver involvement in obese children (ultrasonography and liver enzyme levels at diagnosis and during follow-up in an Italian population). Digestive diseases and sciences 42(7), 1428-1432.

Serviddio, G et al. (2013). Free radical biology for medicine: learning from nonalcoholic fatty liver disease. Free Radical Biology and Medicine 65, 952-968.

Shi, $\mathrm{Z}$ et al. (2017). Antitumor activity and structure-activity relationship of seven lanostane-type triterpenes from 
Fomitopsis pinicola and F. officinalis: Zhongguo zhongyao zazhi. China journal of Chinese materia medica 42(5), 915-922.

Shin, K et al. (2010). Purification and characterization of a thermostable xylanase from Fomitopsis pinicola. $J$. Microbiol. Biotechnol 20(10), 1415-1423.

Shin, K et al. (2010). Purification and characterization of a thermostable cellobiohydrolase from Fomitopsis pinicola. J Microbiol Biotechnol 20(12), 1681-1688.

Siegel, R et al. (2013). CA: A cancer journal for clinicians 63(1), 11-30.

Sies, H. (1997). Oxidative stress: oxidants and antioxidants. Experimental Physiology: Translation and Integration $82(2), 291-295$.

Soares, GM et al. (2001). Decolorization of an anthraquinone-type dye using a laccase formulation. Bioresource Technology 79(2), 171-177.

Song, $\mathrm{M}$ et al. (2018). FPOA induces the apoptosis of HepG2 cells. Experimental and therapeutic medicine 15(3), 2649-2654.

Spiegelman, BM et al. (2001). Obesity and the regulation of energy balance. Cell 104(4), 531-543.

Sudharshan, S et al. (2012). DDT remediation in contaminated soils: a review of recent studies. Biodegradation 23(6), 851-863.

Sun, HH et al. (2009). Isolation, chemical characteristics and antioxidant properties of the polysaccharides from marine fungus Penicillium sp. F23-2. Carbohydrate polymers 78(1), 117-124.

SUN X et al. (2012). Antitumor Active Constituent in Fruiting Body of Fomitopsis pinicola [J]. Lishizhen Medicine and Materia Medica Research 7.

Teeri, TT et al. (1987). Homologous domains in Trichoderma reesei cellulolytic enzymes: gene sequence and expression of cellobiohydrolase II. Gene 51(1), 43-52.

Wald, $\mathrm{N}$ et al. (1995). Serum cholesterol and ischaemic heart disease. Atherosclerosis 118, S1-S5.

Wang, Y et al. (2014). Investigating migration inhibition and apoptotic effects of Fomitopsis pinicola chloroform extract on human colorectal cancer SW-480 cells. PloS one 9(7), e101303.

$\mathrm{Wu}, \mathrm{HT}$ et al. (2014). In vivo and in vitro anti-tumor effects of fungal extracts. Molecules 19(2), 2546-2556.

Yoon, JJ et al. (2008). Degradation of cellulose by the major endoglucanase produced from the brown-rot fungus Fomitopsis pinicola. Biotechnology letters 30(8), 1373-1378.

Yoshikawa, K et al. (2005). Lanostane Triterpenoids and Triterpene Glycosides from the Fruit Body of Fomitopsis p inicola and Their Inhibitory Activity against COX-1 and COX-2. Journal of natural products 68(1), 69-73.

Younossi, ZM et al. (2002). Nonalcoholic fatty liver disease: an agenda for clinical research. Hepatology 35(4), 746-752.

Yuen, JW et al. (2005). Anticancer effects of Ganoderma lucidum: a review of scientific evidence. Nutrition and cancer 53(1), 11-17.

Zhang, M et al. (2009). Dietary intakes of mushrooms and green tea combine to reduce the risk of breast cancer in Chinese women. International journal of cancer 124(6), 1404-1408.

Zhang, YHP et al. (2006). Outlook for cellulase improvement: screening and selection strategies. Biotechnology advances 24(5), 452-481.

Zhao, Y et al. (2010). Chitin deacetylases: properties and applications. Marine drugs 8(1), 24-46. 